University of Nebraska - Lincoln

DigitalCommons@University of Nebraska - Lincoln

4-9-2006

\title{
The electronic structure of $1,2-\mathrm{PCB}_{10} \mathrm{H}_{11}$ molecular films: a precursor to a novel semiconductor
}

\author{
Snjezana Balaz \\ University of Nebraska-Lincoln, sbalaz@ysu.edu \\ D.I. Dimov \\ University of Salford, Salford, UK \\ N.M. Boag \\ University of Nebraska-Lincoln \\ K. Nelson \\ University of Nebraska-Lincoln \\ B. Montag \\ University of Nebraska-Lincoln \\ See next page for additional authors
}

Follow this and additional works at: https://digitalcommons.unl.edu/physicsdowben

Part of the Physics Commons

Balaz, Snjezana; Dimov, D.I.; Boag, N.M.; Nelson, K.; Montag, B.; Brand, Jennifer I.; and Dowben, Peter A., "The electronic structure of 1,2-PCB $10 \mathrm{H}_{11}$ molecular films: a precursor to a novel semiconductor" (2006). Peter Dowben Publications. 109.

https://digitalcommons.unl.edu/physicsdowben/109

This Article is brought to you for free and open access by the Research Papers in Physics and Astronomy at DigitalCommons@University of Nebraska - Lincoln. It has been accepted for inclusion in Peter Dowben Publications by an authorized administrator of DigitalCommons@University of Nebraska - Lincoln. 
Authors

Snjezana Balaz, D.I. Dimov, N.M. Boag, K. Nelson, B. Montag, Jennifer I. Brand, and Peter A. Dowben 

S. BALAZ ${ }^{1}$
D. I. Dimov ${ }^{2}$
N. M. BoAG ${ }^{1,2}$
K. NELSON ${ }^{3}$
B. MontaG ${ }^{3}$
J. I. BRAND ${ }^{3}$
P. A. Dowben ${ }^{1, *}$

\section{The electronic structure of $1,2-\mathrm{PCB}_{10} \mathrm{H}_{11}$ molecular films: a precursor to a novel semiconductor}

\author{
${ }^{1}$ Department of Physics and Astronomy and the Center for Materials Research and Analysis, Behlen Labo- \\ ratory of Physics, University of Nebraska-Lincoln, P. O. Box 880111, Lincoln, NE 68588-0111 USA \\ ${ }^{2}$ Chemistry and Nanotechnology, Institute for Materials Research, Cockcroft Building, University of Sal- \\ ford, Salford M5 4WT, UK \\ ${ }^{3}$ College of Engineering and Technology, N245 Walter Scott Engineering Center, 17th \& Vine Streets, Uni- \\ versity of Nebraska-Lincoln, Lincoln, Nebraska 68588-0511, USA
}

Submitted January 2006; accepted February 28, 2006; Published online April 6, 2006

\begin{abstract}
The band gaps and electronic structure of undoped films of molecular icosahedra of closo-1-phospha-2carbadodecaborane $\left(1,2-\mathrm{PCB}_{10} \mathrm{H}_{11}\right)$ are reported. 1,2- $\mathrm{PCB}_{10} \mathrm{H}_{11}$ adsorbs on $\mathrm{Au}$ and $\mathrm{Ag}$ substrates to generate molecular thin films with the Fermi level(chemical potential) placed closer to the lowest unoccupied molecular orbital than has been observed with closo-1,2-dicarbadodecaborane $\left(1,2-\mathrm{C}_{2} \mathrm{~B}_{10} \mathrm{H}_{12}\right.$, orthocarborane) adsorbed on $\mathrm{Co}$, $\mathrm{Cu}$ or Ag. Both 1,2-PCB ${ }_{10} \mathrm{H}_{11}$ and $1,2-\mathrm{C}_{2} \mathrm{~B}_{10} \mathrm{H}_{12}$ molecular films exhibit an unoccupied molecular defect state above the Fermi level. The vibrational modes, observed in infra-red absorption, are close to the values expected for the isolated 1,2- $\mathrm{PCB}_{10} \mathrm{H}_{11}$ molecule. Consistent with the placement of the Fermi level in the molecular films, fabrication of heterojunction diodes from partially dehydrogenated 1,2- $\mathrm{PCB}_{10} \mathrm{H}_{11}$ indicates that the resultant PCB${ }_{10} \mathrm{H}_{x}$ semiconductor film is more $n$-type than the corresponding boron carbide semiconductor formed from $1,2-\mathrm{C}_{2} \mathrm{~B}_{10} \mathrm{H}_{12}$, orthocarborane.
\end{abstract}

\section{Introduction}

The ability to generate semiconducting grades of boron carbide by plasma enhanced chemical vapor phase deposition (PECVD) of carboranes permits the development of corrosion resistant, high temperature devices with many applications including neutron detection [1-7]. It is now clear that these boron carbides, of approximate stoichiometry " $\mathrm{C}_{2} \mathrm{~B}_{10} \mathrm{H}_{x}$ " (where $x$ represents up to $\sim 5 \%$ molar fraction of hydrogen), exhibit a range of electronic properties (e. g., $p$-type or $n$-type) presumably as a result of differing electronic structures originating in differences in polytype (molecular structure) [7, 8].

These films may be doped "conventionally" with dopants such as iron [9-12], vanadium [12], chromium [12] and nickel [12-16], however, main group doping has not been so successful. The difficulties in using main group elements as dopants in semiconducting boron carbides led to the exploration of the dimeric complex phosphorus bridged orthocarborane $\left(1,2-\mathrm{C}_{2} \mathrm{~B}_{10} \mathrm{H}_{10} \mathrm{PCl}\right)_{2}[8,14]$ as a precursor with 'built-in' dop- ant (P). Although this produced a boron carbide with a significantly larger band gap than the undoped material, phosphorus inclusion was disappointingly variable and never higher than $3 \%$, suggestive of loss during deposition [8, 14]. Since " $\mathrm{C}_{2} \mathrm{~B}_{10} \mathrm{H}_{x}$ " is undoubtedly built up of icosahedral cages, we felt that a precursor that contains a phosphorus atom as an integral part of an icosahedral cage structure might prove more satisfactory in regard to phosphorus incorporation in the final film and led us to consider the use of $1,2-\mathrm{PCB}_{10} \mathrm{H}_{11}$ as a precursor.

We have shown that although the molecular films of different isomers of closo-dicarbadodecaborane $\left(\mathrm{C}_{2} \mathrm{~B}_{10} \mathrm{H}_{12}\right)$ appear to show similar gaps between the highest occupied molecular orbital (HOMO) and lowest unoccupied molecular orbital (LUMO), the placement of the chemical potential in metacarborane films (closo-1,7-dicarbadodecaborane, 1,7- $\mathrm{C}_{2} \mathrm{~B}_{10} \mathrm{H}_{12}$ ) differs significantly from $1,2-\mathrm{C}_{2} \mathrm{~B}_{10} \mathrm{H}_{12}$ (orthocarborane) films $[7,17]$. This difference in the placement of the chemical potential (Fermi level, $E_{\mathrm{F}}$ ) is difficult to understand, as both molecules have identical electron counts and symmetry. The differences are also observed in the gas phase and thus may be an integral feature of orthocarborane and metacarborane molecules $[17,18]$. A possible explanation for the difference in the placement of the chemical potential may be in part due to the presence of the carbon-carbon bond and the possibility of multiple bond character between the two carbon atoms [17, 18]. Accordingly, the study described on an isoelectronic analogue to $1,2-\mathrm{C}_{2} \mathrm{~B}_{10} \mathrm{H}_{12}$, viz $1,2-\mathrm{PCB}_{10} \mathrm{H}_{11}$, which lacks a $\mathrm{C}-\mathrm{C}$ bond will provide some insight into this matter.

Herein, we compare thin layers of adsorbed molecular 1,2- $\mathrm{PCB}_{10} \mathrm{H}_{11}$ on $\mathrm{Au}$ and $\mathrm{Ag}$ substrates with those of 1,2$\mathrm{C}_{2} \mathrm{~B}_{10} \mathrm{H}_{12}$ as well as the related partially dehydrogenated boron carbide semiconductor films formed by plasma enhanced chemical vapor deposition, from these two source molecules. By replacing carbon with phosphorus, the possibility of multiple bond character between two vertex atoms is retained, but the $\mathrm{C}_{2 v}$ point group symmetry of $1,2-\mathrm{C}_{2} \mathrm{~B}_{10} \mathrm{H}_{12}$ is lifted (reduced to $\mathrm{C}_{1 \mathrm{~h}}$ ). We show that some surprising differences exist for these molecules, when adsorbed on metal surfaces. We

\footnotetext{
*Correspondence_Fax: 402-472-2879; email: pdowben@unl.edu
} 
have previously reported that the electronic structure of carborane thin films frequently provides indications of the likely band offsets exhibited by those of the boron carbide deposited by PECVD from the same carborane. This feature appears to be true of the properties of molecular thin films of closo1-phospha-2-carbadodecaborane $\left(1,2-\mathrm{PCB}_{10} \mathrm{H}_{11}\right)$ when compared to the electronic properties of the doped boron carbide thin films that can be generated by (partial) dehydrogenation of this source molecule, through PECVD.

\section{Experimental}

1,2- $\mathrm{PCB}_{10} \mathrm{H}_{11}$ was prepared in $41 \%$ yield by the method of Little and Todd from the reaction of $\mathrm{Na}_{3}\left[\mathrm{CB}_{10} \mathrm{H}_{11}\right]$ and $\mathrm{PCl}_{3}$ $[19,20]$. The resultant pale yellow powder was sublimed at $100{ }^{\circ} \mathrm{C}$ and $0.01 \mathrm{mmHg}$ to afford a white crystalline mass. Purity was confirmed by NMR spectroscopy (and infra-red spectroscopy, as described later). Decaborane was purchased from Katchem [21]. THF was distilled from sodium/benzephenone just prior to use.

NMR spectra were obtained on a Bruker AVANCE400 operating at ${ }^{1} \mathrm{H} 400 . \mathrm{MHz},{ }^{31} \mathrm{P} 161.9 \mathrm{MHz}{ }^{13} \mathrm{C} 100.6 \mathrm{MHz}$, ${ }^{11} \mathrm{~B} 128.4 \mathrm{MHz}$. Proton and carbon spectra were referenced to solvent, boron spectra to an insert of $\mathrm{BF}_{3} \cdot \mathrm{Et}_{2} \mathrm{O}(0.0 \mathrm{ppm})$ and phosphorus spectra to an insert of $\mathrm{P}(\mathrm{OPh})_{3}(126.5 \mathrm{ppm})$. $\operatorname{NMR}\left(\mathrm{C}_{6} \mathrm{D}_{6}\right):{ }^{11} \mathrm{~B} 9.7\left(\mathrm{~B}_{12}, J_{\mathrm{BH}}=148 \mathrm{~Hz}\right), 2.6\left(\mathrm{~B} 9 J_{\mathrm{BH}} 151\right.$ $\mathrm{Hz}),-0.9\left(\mathrm{~B} 8 / 10, J_{\mathrm{BH}}=152 \mathrm{~Hz}\right),-7.3\left(\mathrm{~B} 7 / 11, J_{\mathrm{BH}} 167 \mathrm{~Hz}\right)$, $-7.8\left(\mathrm{~B} 4 / 5, J_{\mathrm{BH}}=158 \mathrm{~Hz}, J_{\mathrm{BP}}=63 \mathrm{~Hz}\right),-12.0\left(\mathrm{~B} 3 / 6, J_{\mathrm{BH}}\right.$ $\left.=169 \mathrm{~Hz}, J_{\mathrm{BP}}=47 \mathrm{~Hz}\right) ;{ }^{31} \mathrm{P}\left\{{ }^{1} \mathrm{H}\right\}-58.9 \mathrm{ppm} ;{ }^{1} \mathrm{H} /{ }^{1} \mathrm{H}\left\{{ }^{11} \mathrm{~B}\right\}$ 3.34(s, H12), 3.06 (s, H8/10), 3.03 (s, H9), 2.43 (s, H7/11), $2.12\left(\mathrm{~d}, \mathrm{H} 3 / 6,{ }^{2} J_{\mathrm{HP}} \sim 20 \mathrm{~Hz}\right), 2.10$ (s, H4/5), 2.02(d, H2, ${ }^{2}$ $\left.J_{\mathrm{HP}}=14.5 \mathrm{~Hz}\right) ;{ }^{13} \mathrm{C}\left\{{ }^{1} \mathrm{H}\right\} 66.6\left({ }^{1} J_{\mathrm{PC}}=59 \mathrm{~Hz}\right)$. The assignment of the boron and proton resonances was confirmed by ${ }^{11} \mathrm{~B}-{ }^{11} \mathrm{~B}$ and ${ }^{1} \mathrm{H}\left\{{ }^{11} \mathrm{~B}\right\}-{ }^{11} \mathrm{~B}\left\{{ }^{1} \mathrm{H}\right) \mathrm{COSY}$ spectra. The ${ }^{11} \mathrm{~B}-{ }^{11} \mathrm{~B}$ COSY spectrum resolved both the proton and phosphorus coupling to B3B6 confirming the assignment of their resonances determined through cross peak analysis. The numbering scheme is given in Fig. 1.

The molecular thin film sample preparation and subsequent electron spectroscopy data acquisition were performed in two UHV chambers, both with base pressures of $5 \times 10^{-11}$ Torr. Film growth and substrate preparation has been described in detail elsewhere [22]. For the inverse photoemission studies, a Geiger-Müller detector fitted with a $\mathrm{SrF}_{2}$ window of $9.5 \mathrm{eV}$ pass energy was used in conjunction with an Erdman-Zipf electron gun [23]. The overall energy resolution was $\sim 0.40$ $\mathrm{eV}$. All IPES spectra were collected with the electron gun at normal incidence and the detector positioned at $45^{\circ}$ off the surface normal. The acquisition of the photoemission spectra has been described elsewhere [22], with the photoelectrons collected along the surface normal. The Fermi level was established from the clean, well ordered $\mathrm{Cu}, \mathrm{Ag}$ or $\mathrm{Au}$ substrate as appropriate. Photoemission spectroscopy data were taken using a photon energy of $65 \mathrm{eV}$ using synchrotron radiation, dispersed by a $3 \mathrm{~m}$ toroidal grating monochromator at normal incidence to the film, at the Center for Advance Microstructures

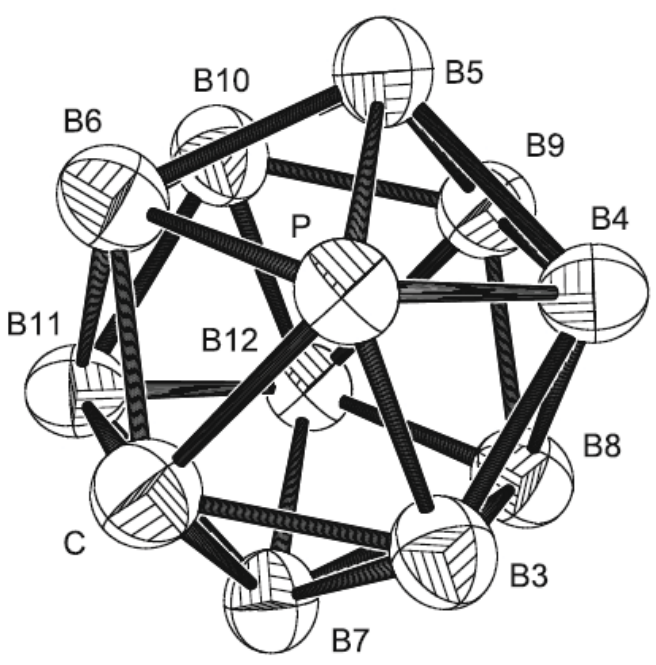

FIGURE 1 The structure of closo-1-phospha-2-carbadodecaborane $\left(1,2-\mathrm{PCB}_{10} \mathrm{H}_{11}\right)$ with the ellipsoids set at the $50 \%$ probability level and hydrogen atoms omitted for clarity. The unique positions are arbitrarily labeled as $\mathrm{P}$ and $\mathrm{C}$ and the remaining atoms as $\mathrm{B}$ using the conventional numbering scheme.

and Devices. 1,2- $\mathrm{PCB}_{10} \mathrm{H}_{11}$ was deposited on both $\mathrm{Ag}$ and $\mathrm{Au}$ substrates cooled to $180 \mathrm{~K}$, and admitted to both UHV chambers through a standard leak valve at the base pressure of $2 \times$ $10^{-6}$ Torr. The $1,2-\mathrm{C}_{2} \mathrm{~B}_{10} \mathrm{H}_{12}$ was deposited on both $\mathrm{Cu}(100)$ and $\mathrm{Ag}$ substrates, also cooled to $180 \mathrm{~K}$, and admitted to both UHV chambers through a standard leak valve at the base pressure of $2 \times 10^{-7}$ Torr, as described elsewhere [7, 17, 22].

The solid 1,2- $\mathrm{PCB}_{10} \mathrm{H}_{11}$ samples were placed in a $\mathrm{KBr}$ pellet and the Fourier transform infrared absorption spectra run with a globar source at the Center for Advance Microstructures and Devices, as described elsewhere [24].

The diodes were constructed using the process of PECVD (plasma enhanced chemical vapor deposition) as described for the heterojunction $[1-4,15,16]$ and homojunction diodes [13] of boron-carbide as well as diodes made from two polytypes of boron-carbide [5-7], but with only carboranes and argon as the plasma reactor gases.

\section{Crystallographic data and structure of the molecular solid}

Data were collected using a Siemens P4 diffractometer at $223 \mathrm{~K}$ on a colorless rhombahedron mounted on a glass pin. Following data collection (Table 1), the structure was solved using Direct Methods in the cubic space group Pa-3. Like most simple icosahedral borane-based molecules, the molecule was disordered which did not permit assignment of a particular atom type to the two independent positions present in this high symmetry space group. The structure was, therefore, refined using $\mathrm{P}, \mathrm{C}$ and $\mathrm{B}$ atoms in the appropriate occupancy ratio $(1: 1: 10)$ constrained to identical positional and thermal parameters. Hydrogen atoms were identified and their positional parameter refined using an 11/12 occupancy with the thermal parameter tied to the appropriate heavy atom. The molecular structure is shown in Fig. 1 with the two unique po- 


\begin{tabular}{|c|c|}
\hline Empirical formula & $\mathrm{CH}_{11} \mathrm{~B}_{10} \mathrm{P}$ \\
\hline Formula weight & 162.17 \\
\hline Temperature & $223(2) \mathrm{K}$ \\
\hline Wavelength & $0.71073 \AA$ \\
\hline Crystal system & Cubic \\
\hline Space group & $\mathrm{Pa}-3$ \\
\hline \multirow[t]{3}{*}{ Unit cell dimensions } & $a=9.7026(6) \AA \quad \alpha=90^{\circ}$ \\
\hline & $b=9.7026(6) \AA \quad \beta=90^{\circ}$ \\
\hline & $c=9.7026(6) \AA \quad \gamma=90^{\circ}$ \\
\hline Volume & $913.41(10) \AA^{3}$ \\
\hline $\mathrm{Z}$ & 4 \\
\hline Density (calculated) & $1.179 \mathrm{Mg} / \mathrm{m}^{3}$ \\
\hline Absorption coefficient & $0.217 \mathrm{~mm}^{-1}$ \\
\hline $\mathrm{F}(000)$ & 328 \\
\hline Crystal size & $0.4 \times 0.25 \times 0.20 \mathrm{~mm}^{3}$ \\
\hline Theta range for data collection & 3.64 to $27.41^{\circ}$ \\
\hline Index ranges & $\begin{array}{l}-12<=h<=1,-1<=k<=12, \\
-12<=l<=1\end{array}$ \\
\hline Reflections collected & 1438 \\
\hline Independent reflections & $354[R$ (int $)=0.0344]$ \\
\hline Completeness to theta $=27.41^{\circ}$ & $100.0 \%$ \\
\hline Absorption correction & psi-scan \\
\hline Max. and min. transmission & 0.86837 and 0.85748 \\
\hline Refinement method & Full-matrix least-squares on $\mathrm{F}^{2}$ \\
\hline Data/restraints/parameters & $354 / 0 / 28$ \\
\hline Goodness-of-fit on $\mathrm{F}^{2}$ & 1.091 \\
\hline Final $R$ indices $[I>2 \operatorname{sigma}(I)]$ & $R_{1}=0.0503, w R_{2}=0.1318$ \\
\hline$R$ indices (all data) & $R_{1}=0.0651, w R_{2}=0.1448$ \\
\hline Largest diff. peak and hole & 0.188 and $-0.220 \mathrm{e} . \bar{\AA}^{-3}$ \\
\hline $\mathrm{B}(1)-\mathrm{B}(2)$ & $1.859(2)$ \\
\hline $\mathrm{B}(1)-\mathrm{B}(1) \# 3$ & $1.892(3)$ \\
\hline $\mathrm{B}(2)-\mathrm{B}(2) \# 2$ & $1.8284(19)$ \\
\hline $\mathrm{B}(2) \# 1-\mathrm{B}(1)-\mathrm{B}(2) \# 2$ & $105.43(12)$ \\
\hline $\mathrm{B}(2) \# 1-\mathrm{B}(1)-\mathrm{B}(1) \# 3$ & $106.67(8)$ \\
\hline $\mathrm{B}(2) \# 2-\mathrm{B}(2)-\mathrm{B}(2) \# 1$ & $107.95(9)$ \\
\hline $\mathrm{B}(2) \# 2-\mathrm{B}(2)-\mathrm{B}(1) \# 1$ & $109.36(8)$ \\
\hline
\end{tabular}

Symmetry transformations used to generate equivalent atoms:

$\# 1-z,-x,-y ; \# 2-y,-z,-x ; \# 3 z, x, y$

TABLE 1 Crystal structure data, bond lengths $[\AA]$ and angles $\left[{ }^{\circ}\right]$ for closo-1-phospha-2-carbadodecaborane $\left(1,2-\mathrm{PCB}_{10} \mathrm{H}_{11}\right)$.

sitions arbitrarily assigned as $\mathrm{P}$ and $\mathrm{C}$ and the remaining atoms being labeled as B in the appropriate numbering scheme.

Within the icosahedral structure there are thirty interatomic bonds; one $\mathrm{P}-\mathrm{C}$ bond, $4 \mathrm{P}-\mathrm{B}$ bonds, $4 \mathrm{C}-\mathrm{B}$ bonds and $21 \mathrm{~B}-\mathrm{B}$ bonds. The high symmetry of the disordered structure results in only three unique bonding distances, 1.892(3), 1.8285(19) and $1.859(3) \AA$. Using bond distance data from the literature [25-32] obtained from less symmetric molecules, electron diffraction data or molecules co-crystallized with hydrogen bond acceptors, one can estimate approximate values for these various bonds. Averaging gives a value of $1.83 \AA$, close to the values found, as summarized in Table 1.

The solid-state structure of $1,2-\mathrm{C}_{2} \mathrm{~B}_{10} \mathrm{H}_{12}$ has not been determined in the absence of hydrogen bonding acceptors, although a great deal of information is known about the temperature dependent phases that this molecule exhibits $[33,34]$. Significantly, the high temperature phases of $1,2-\mathrm{C}_{2} \mathrm{~B}_{10} \mathrm{H}_{12}$ exhibit isotropic and anisotropic molecular reorientations, a phenomenon known as plasticity, and an ordered phase is not observed until below $120 \mathrm{~K}$. Only the high temperature phase $(>310 \mathrm{~K}$ ) is cubic (fcc, $Z=4, a$ $=9.855 \AA$ ) with the lower temperature phases exhibiting increasingly lower crystal symmetry [33]. By contrast, the single crys- tal structure of 1,2- $\mathrm{PCB}_{10} \mathrm{H}_{11}$ at $223 \mathrm{~K}$ reveals a cubic space group Pa-3 (no. 205) with $a=9.7026(6) \AA$ and four molecules per unit cell suggests that the increased asymmetry of this molecule leads to a loss of plasticity, at least in the temperature range studied.

As with other carborane cage molecules [35], the first layer of $1,2-\mathrm{C}_{2} \mathrm{~B}_{10} \mathrm{H}_{12}$ bonds to the $\mathrm{Cu}(100)$ substrate through the acidic hydrogens on carbon or partly dehydrogenates at the interface to bond directly via the carbon to the metal substrate [22]. 1,2- $\mathrm{C}_{2} \mathrm{~B}_{10} \mathrm{H}_{12}$ lacks any apparent preferential orientation for coverages exceeding a monolayer [22]. Surprisingly, however, on $\mathrm{Co}(111)$ some preferential orientation appears to be retained within the film above the first monolayer [36]. Thus, strong substrate interactions might lead to some limited orientational preference, but the intermolecular interactions do not provide sufficient orientational ordering in the molecular crystal. Similar behavior may occur with $1,2-\mathrm{PCB}_{10} \mathrm{H}_{11}$.

The disorder found in the crystal structure of $1,2 \mathrm{PCB}_{10} \mathrm{H}_{11}$, by X-ray diffraction, suggests that it is very unlikely that any orientational ordering in thin films of this material will be observed in the bulk.

\section{Theory}

For the work described here, the ground-state energies were calculated using a PM3 model calculation with the HyperChem package as well as using modified neglect of differential overlap (MNDO) [37, 38]. Similar semi-empirical calculations [7, $17,22,39$ ] have been found to provide good agreement with photoemission and inverse photoemission experiments, in spite of the simplistic methodology and the fact that these are ground state calculations [18]. These semi-empirical calculations of occupied and unoccupied molecular orbitals were undertaken following geometry optimization and the calculation of the lowest restricted Hartree-Fock (RHF) energy states. Our calculated bond lengths of $1.809 \AA$ for the average B-B bond, 1.7612 $\AA$ for the average B-C bond, 2. $0488 \AA$ for the average P-B bond and 2. $076 \AA$ for the $\mathrm{P}-\mathrm{C}$ bond agrees well with that obtained from $a b$ initio theory [40] derived values of $1.813 \AA$ (BB), $1.777 \AA$ (B-C), 2. $070 \AA$ (P-B) and 2. $031 \AA(\mathrm{P}-\mathrm{C})$. The weighted average of bond lengths calculated here $(1.8435 \AA)$ and by using $a b$ initio theory (1.85 $\AA$ ) are in good agreement with the experimental values of $1.83 \AA$ to $1.89 \AA$.

We have compared our semi-empirical calculations with density functional theory (DFT) for a variety of carborane clusters [41]. Although the total energy is probably better estimated using DFT, there are, however, serious deficiencies in using ab initio DFT to model electronic structure of the closocarboranes. Ab initio molecular calculations have been undertaken for ortho-phosphacarborane $\left(1,2-\mathrm{PCB}_{10} \mathrm{H}_{11}\right)$ [40, 42], but the electronic structure was not provided by the authors.

For the work undertaken here, a calculated density of states was obtained by applying equal Gaussian envelopes of $1 \mathrm{eV}$ width to each molecular orbital binding energies (to account for the solid state broadening in photoemission) and then summing, in addition to a rigid energy shift applied to the calculated electronic structure. 


\section{Electronic structure of the molecular films}

Orthocarborane $\left(1,2-\mathrm{C}_{2} \mathrm{~B}_{10} \mathrm{H}_{12}\right)$ adsorbs associatively on $\mathrm{Cu}(100)$ and $\mathrm{Ag}$ at low temperatures $(\sim 180 \mathrm{~K})[7,22]$ and molecularly desorbs from $\mathrm{Cu}(100)$ at approximately $450 \mathrm{~K}$ [22]. If anything, 1,2- $\mathrm{PCB}_{10} \mathrm{H}_{11}$ is more weakly bound to $\mathrm{Ag}$ and $\mathrm{Au}$ substrates. Thus although, 1,2- $\mathrm{PCB}_{10} \mathrm{H}_{11}$ also adsorbs at low temperatures $(\sim 180 \mathrm{~K}), 1,2-\mathrm{PCB}_{10} \mathrm{H}_{11}$ molecularly desorbs at approximately $300 \mathrm{~K}$, as indicated by the combined photoemission and inverse photoemission spectra. This is consistent with our estimates that the sticking coefficient for 1,2$\mathrm{PCB}_{10} \mathrm{H}_{11}$ is 18 times smaller than for $1,2-\mathrm{C}_{2} \mathrm{~B}_{10} \mathrm{H}_{12}$ on noble metal surfaces. From the attenuation of the substrate valence band signal, we estimate that exposure of the $\mathrm{Cu}(100)$ and $\mathrm{Ag}$ surfaces, at $180 \mathrm{~K}$, to 8 Langmuirs ( $1 \mathrm{~L}=10^{-6}$ Torr $\left.\cdot \mathrm{sec}\right) 1,2-$ $\mathrm{C}_{2} \mathrm{~B}_{10} \mathrm{H}_{12}$ results in completion of a monolayer, whereas 120 Langmuirs of 1,2- $\mathrm{PCB}_{10} \mathrm{H}_{11}$ was required to generate a monolayer on $\mathrm{Ag}$ substrates at $180 \mathrm{~K}$. This corresponds to a sticking coefficient of 0.18 for $1,2-\mathrm{C}_{2} \mathrm{~B}_{10} \mathrm{H}_{12}$ (orthocarborane) and a sticking coefficient of 0.01 for $1,2-\mathrm{PCB}_{10} \mathrm{H}_{11}$ (ortho-phosphacarborane) assuming an ion gauge cross-section identical to N2 and a density of $4 \times 10^{18}$ molecules $/ \mathrm{m}^{2}$ for a monolayer (ML). The ordering of the sticking coefficients thus appears somewhat related to the number of $\mathrm{C}-\mathrm{H}$ bonds.

In Fig. 2 we present a series of both inverse photoemission electron spectroscopy (IPES) and photoemission electron spectroscopy (PES) spectra of 1,2-PCB ${ }_{10} \mathrm{H}_{11}$ films on $\mathrm{Ag}(111)$ as a function of film thickness. Film thicknesses of up to 12.2 monolayers (ML) are shown. With adsorption of 1,2- $\mathrm{PCB}_{10} \mathrm{H}_{11}$, the unoccupied s-p band and the image state $(\sim 4.3 \mathrm{eV})$ of the Ag substrate are suppressed, as are the occupied Ag 4d bands. The lowest unoccupied molecular orbitals (LUMO) become discernible at approximately 5-7 ML of

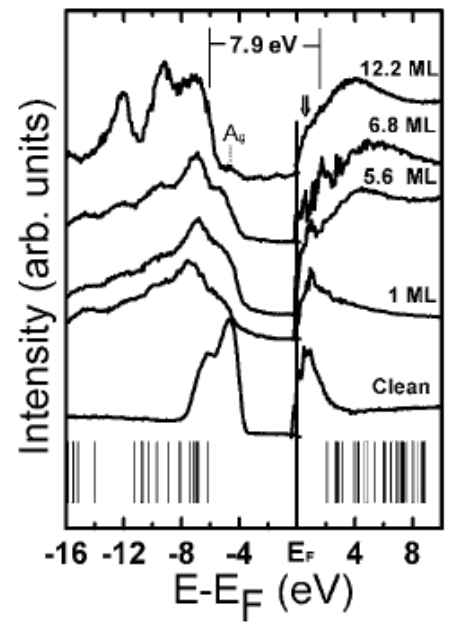

FIGURE 2 Normal emission photoemission and normal incidence inverse photoemission spectra of $1,2-\mathrm{PCB}_{10} \mathrm{H}_{11}$ on $\mathrm{Ag}(111)$ as a function of coverage in molecular monolayers (ML). The photoemission spectra were acquired with a photon energy of $65 \mathrm{eV}$. Vertical lines represent the theoretical molecular orbital binding energies (at the bottom of the figure) and provide a HOMO-LUMO gap of $8.3 \mathrm{eV}$ compared to the experimental HOMO-LUMO gap of $7.9 \mathrm{eV}$, as indicated. coverage at an energy of about $2.5 \mathrm{eV}$ above the Fermi level. The highest occupied molecular orbitals (HOMO) are readily apparent in the photoemission spectra at a binding energy of about $6.2 \pm 0.3 \mathrm{eV}$ below the Fermi level as the Ag substrate signal is suppressed with increasing 1,2- $\mathrm{PCB}_{10} \mathrm{H}_{11}$ coverage, as seen in Fig. 2. The highest occupied (HOMO) to lowest unoccupied (LUMO) gap was observed to be $7.9 \pm 0.4 \mathrm{eV}$ from the combined photoemission and inverse photoemission measurements, in reasonable agreement with our calculated value of $8.27 \mathrm{eV}$, as summarized in Fig. 3.

This type of agreement between calculated and experimental values for the highest occupied (HOMO) to lowest unoccupied (LUMO) gap appears to be typical of the closo carboranes. Although somewhat larger, the HOMO to LUMO gaps for 1,2- $\mathrm{C}_{2} \mathrm{~B}_{10} \mathrm{H}_{12}$ on copper and silver $(11.3 \mathrm{eV})$ and 1,7$\mathrm{C}_{2} \mathrm{~B}_{10} \mathrm{H}_{12}$ (metacarborane) on silver and gold (10.0 eV), based on the binding energies derived from photoemission and inverse photoemission, are in reasonable agreement with theory (10.97 eV and $10.92 \mathrm{eV}$ respectively using the MNDO method and 10. eV and 10. $0 \mathrm{eV}$, respectively, using the PM3 method) $[7,17]$, as indicated in Fig. 3. We attribute the smaller HOMO-LUMO gap in 1,2- $\mathrm{PCB}_{10} \mathrm{H}_{11}$, when compared to 1,2$\mathrm{C}_{2} \mathrm{~B}_{10} \mathrm{H}_{12}$, as due in part to the strain arising from incorporation of the larger phosphorus atom into the icosahedral cage.

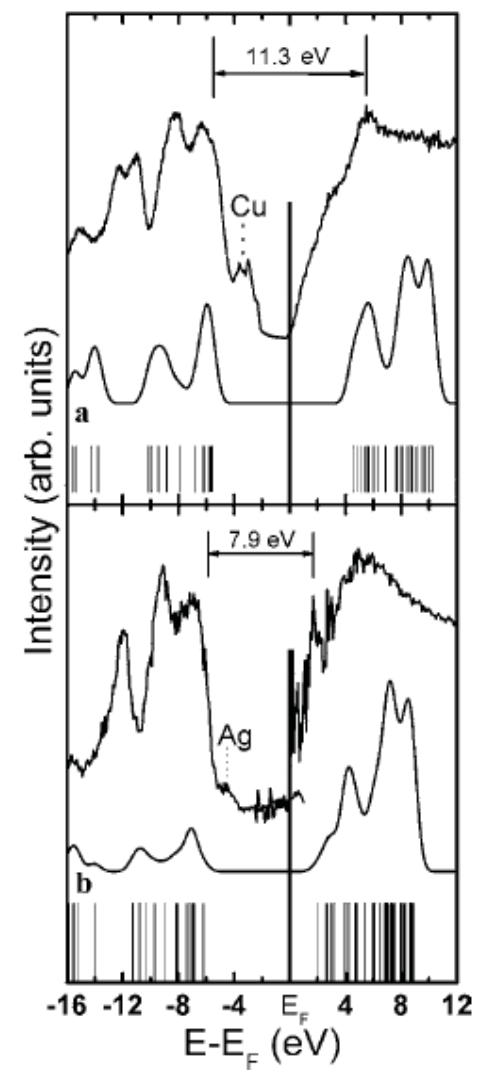

FIGURE 3 Combined UPS (left) and IPES (right) spectra (solid line) of molecular films of $1,2-\mathrm{C}_{2} \mathrm{~B}_{10} \mathrm{H}_{12}$ (a) and 1,2- $\mathrm{PCB}_{10} \mathrm{H}_{11}(\mathbf{b})$, along with the calculated density-of-states for each molecule. The UPS and IPES signals are related to the contributions from the occupied and unoccupied molecular orbitals, respectively. The experimental HOMO-LUMO gaps are indicated. 
From our results in Figs. 2 and 3, we see that the band gap of the molecular 1,2- $\mathrm{PCB}_{10} \mathrm{H}_{11}$ film is largely determined by the molecular HOMO-LUMO gap.

As noted elsewhere [7], there is very little difference in the observed electronic structure of adsorbed molecular orthocarborane $\left(1,2-\mathrm{C}_{2} \mathrm{~B}_{10} \mathrm{H}_{12}\right)$ on $\mathrm{Cu}$ and $\mathrm{Ag}$ substrates at $180 \mathrm{~K}$. The photoemission features of adsorbed molecular orthocarborane $\left(1,2-\mathrm{C}_{2} \mathrm{~B}_{10} \mathrm{H}_{12}\right)$ on $\mathrm{Cu}(100)$, at $-5.7,-8.5$ and $-11.4 \mathrm{eV}$ $\left(E-E_{\mathrm{F}}\right)$, are shifted to slightly higher binding energies for adsorbed molecular orthocarborane $\left(1,2-\mathrm{C}_{2} \mathrm{~B}_{10} \mathrm{H}_{12}\right)$ on $\mathrm{Ag}$ as these features appear at $-5.9 \mathrm{eV},-8.9 \mathrm{eV}$ and $-11.5 \mathrm{eV}$. There are more differences in the observed electronic structure of adsorbed molecular ortho-phosphacarborane $\left(1,2-\mathrm{PCB}_{10} \mathrm{H}_{11}\right)$ on $\mathrm{Ag}$ and $\mathrm{Au}$ substrates at $180 \mathrm{~K}$. The photoemission binding energies for ortho-phosphacarborane $\left(1,2-\mathrm{PCB}_{10} \mathrm{H}_{11}\right)$ on $\mathrm{Ag}$ are at $-7.3,-9.2 \mathrm{eV}$ and $-12 \mathrm{eV}(E-E \mathrm{~F})$, while the photoemission features of ortho-phosphacarborane $\left(1,2-\mathrm{PCB}_{10} \mathrm{H}_{11}\right)$ on $\mathrm{Au}$ are at $-7 .,-8.3 \mathrm{eV}$ and $-11.3 \mathrm{eV}\left(E-E_{\mathrm{F}}\right)$. There are, however, more significant differences between molecular orthocarborane $\left(1,2-\mathrm{C}_{2} \mathrm{~B}_{10} \mathrm{H}_{12}\right)$ and molecular ortho-phosphacarborane $\left(1,2-\mathrm{PCB}_{10} \mathrm{H}_{11}\right)$.

There is an unexpected difference between the placement of the 1,2- $\mathrm{C}_{2} \mathrm{~B}_{10} \mathrm{H}_{12}$ lowest unoccupied (LUMO) band (an $E-$ $E_{\mathrm{F}}$ of $\left.5.6 \mathrm{eV}\right)[7,17]$ and that of the 1,2- $\mathrm{PCB}_{10} \mathrm{H}_{11}$ lowest unoccupied (LUMO) band (an $E-E_{\mathrm{F}}$ of $2.4 \mathrm{eV}$ on Au and an $E$ $-E_{\mathrm{F}}$ of $1.9 \mathrm{eV}$ on $\mathrm{Ag}$ ). The HOMO-LUMO gap center is offset with respect to the Fermi level differently for the two molecules by more than 3 to $4 \mathrm{eV}$, that is to say that the Fermi level is placed some 3 to $4 \mathrm{eV}$ closer to the lowest unoccupied (LUMO) band edge for 1,2- $\mathrm{PCB}_{10} \mathrm{H}_{11}$ than is the case for 1,2$\mathrm{C}_{2} \mathrm{~B}_{10} \mathrm{H}_{12}$. In this regard, 1,2-PCB ${ }_{10} \mathrm{H}_{11}$ more closely resembles $1,7-\mathrm{C}_{2} \mathrm{~B}_{10} \mathrm{H}_{12}[7,19,20]$ and $\mathrm{C}_{60}$ where the Fermi energy lies just below the LUMO (the conduction band minimum) [4345]. Without knowing the majority carrier, we believe these results suggest that $1,2-\mathrm{PCB}_{10} \mathrm{H}_{11}$ forms a molecular semiconducting thin film that is strongly $n$-type compared to the slightly $p$-type and insulating $1,2-\mathrm{C}_{2} \mathrm{~B}_{10} \mathrm{H}_{12}$ molecular films.

This shift in the relative energies of the lowest unoccupied molecular orbitals (relative to the Fermi level) seems to be intrinsic to the differences between 1,2- $\mathrm{PCB}_{10} \mathrm{H}_{11}$ and 1,2$\mathrm{C}_{2} \mathrm{~B}_{10} \mathrm{H}_{12}$. The origin of the differences in molecular orbital placement relative to the Fermi level may, nonetheless, be a solid state effect as the difference in the placement of the chemical potential of this magnitude are not evident in our simple ground state calculations. The calculations of the orbital energies are offset from the experimentally determined values of the condensed phase by approximately $3.9 \mathrm{eV}$ for 1,2- $\mathrm{PCB}_{10} \mathrm{H}_{11}$ while a shift of some $5.3 \mathrm{eV}$ must be applied to the calculated electronic structure of $1,2-\mathrm{C}_{2} \mathrm{~B}_{10} \mathrm{H}_{12}$. The difference between the isolated free cluster and the condensed film can be, in part, accounted for in terms of the work function of the substrate. The differences in this value between $1,2 \mathrm{PCB}_{10} \mathrm{H}_{11}$ and 1,2- $\mathrm{C}_{2} \mathrm{~B}_{10} \mathrm{H}_{12}$ appear to require the inclusion of other solid state effects and consideration of differences in the molecular electron affinities, as work function of $\mathrm{Ag}$ and $\mathrm{Cu}$ surfaces differs little [46]. Furthermore, as noted above, the electronic structure of multilayer molecular films of 1,2$\mathrm{C}_{2} \mathrm{~B}_{10} \mathrm{H}_{12}$ differ little when adsorbed on copper and silver (by about $300 \mathrm{~m} \mathrm{eV}$ ) [7], but are significantly different from molecular 1,2- $\mathrm{PCB}_{10} \mathrm{H}_{11}$ on silver or gold.

The arguments that $1,2-\mathrm{C}_{2} \mathrm{~B}_{10} \mathrm{H}_{12}$ is more " $p$-type" due to the multiple bond character in the $\mathrm{C}-\mathrm{C}$ bond [18] that we have used previously [17] would not seem to fully apply as an intra-icosahedral phosphorus adjacent to carbon should result in 1,2- $\mathrm{PCB}_{10} \mathrm{H}_{11}$ exhibiting similar properties to $1,2-\mathrm{C}_{2} \mathrm{~B}_{10} \mathrm{H}_{12}$. It is true, however, that the electron affinity level is somewhat lower for molecular 1,2- $\mathrm{PCB}_{10} \mathrm{H}_{11}$ (the LUMO orbital energy is at $-1.96 \mathrm{eV}$ from the $\mathrm{PM} 3$ calculations) than for molecular $1,2-\mathrm{C}_{2} \mathrm{~B}_{10} \mathrm{H}_{12}$ (the LUMO orbital energy is at $-0.7 \mathrm{eV}$ from the PM3 calculations) but this roughly $1 \mathrm{eV}$ shift only partly accounts for the 3 to $4 \mathrm{eV}$ shift observed between the 2 molecules, when adsorbed in multilayer films on noble metal substrates.

Molecular symmetry is not a plausible explanation for the shift in molecular orbitals between 1,2- $\mathrm{PCB}_{10} \mathrm{H}_{11}$ and 1,2$\mathrm{C}_{2} \mathrm{~B}_{10} \mathrm{H}_{12}$ and molecular symmetry does not alter the fact that the valence electron counts are identical. Although it is known that a lowering of orbital symmetry can occur with molecular adsorption [47], 1,2- $\mathrm{PCB}_{10} \mathrm{H}_{11}$ has little in the way of symmetry operations as an isolated molecule $\left(\mathrm{C}_{1 \mathrm{~h}}\right)$, so adsorption will change the symmetry very little (if at all) while interface bonding should not affect the surface of a molecular film many molecular layers thick. Interface bonding effects tend to be excluded by the coverage dependence of the electronic structure noted below, and the weak interaction expected with $\mathrm{Au}$ and $\mathrm{Ag}$ substrates.

From difference spectra (although subtracting the photoemission and inverse photoemission spectra to obtain the molecular states of $1,2-\mathrm{PCB}_{10} \mathrm{H}_{11}$ is fraught with considerable uncertainty for low molecular coverages) there is no evidence of band bending or Schottky barrier formation arising from the molecular film to substrate interface. The molecular $1,2-\mathrm{PCB}_{10} \mathrm{H}_{11}$ films are the largely coverage independent molecular orbital binding energies, as plotted

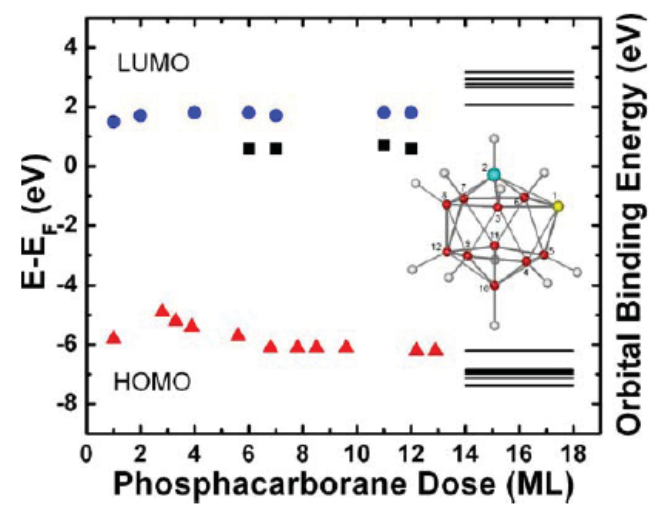

FIGURE 4 The binding energies of the HOMO (triangles), the LUMO (circles), and the exopolyhedral state (squares) of 1,2$\mathrm{PCB}_{10} \mathrm{H}_{11}$ on $\mathrm{Ag}$ and $\mathrm{Au}$, referenced to the substrate Fermi level, as a function of 1,2- $\mathrm{PCB}_{10} \mathrm{H}_{11}$ coverage. Included are the HOMO and LUMO energies of the free clusters which have been derived from PM3 calculations. The inset is an illustration of the 1,2- $\mathrm{PCB}_{10} \mathrm{H}_{11}$. 
in Fig. 4. This is somewhat different from $1,2-\mathrm{C}_{2} \mathrm{~B}_{10} \mathrm{H}_{12}$ molecular films for which increasing coverage shifts the LUMO states to higher energies, i.e., away from the Fermi level, while simultaneously becoming more highly resolved [39]. In Fig. 5, we have also plotted the energy of the HOMO and LUMO states of $1,2-\mathrm{C}_{2} \mathrm{~B}_{10} \mathrm{H}_{12}$, relative to the substrate Fermi level, as a function of coverage. We see that as the film coverage increases the HOMO and LUMO diverge from one another, with the HOMO shifting to higher binding energies and the LUMO to lower binding energies. These shifts do not follow the changes in the work function and therefore are not due to changes in the surface potential. If we consider band bending (an initial state effect) or strong chemical interface effects (also an initial state effect), then we would expect the energies of both the HOMO and the LUMO, relative to the Fermi level, to rigidly shift in the same direction. Since the HOMO and the LUMO symmetrically diverge from one another, and the Fermi level, we can rule out band bending and charge transfer initial state effects in the case of molecular adsorption of either 1,2- $\mathrm{PCB}_{10} \mathrm{H}_{11}$ or $1,2-\mathrm{C}_{2} \mathrm{~B}_{10} \mathrm{H}_{12}$.

We can understand these symmetric shifts of the HOMO and LUMO away from the Fermi level with increasing 1,2$\mathrm{C}_{2} \mathrm{~B}_{10} \mathrm{H}_{12}$ coverage in terms of the influence of the metal substrate [39]. Such shifts have also been observed with increasing $\mathrm{C}_{60}$ coverage on a variety of substrates [48-50], as well as alkane molecular films [51]. As with $1,2-\mathrm{C}_{2} \mathrm{~B}_{10} \mathrm{H}_{12}$, a large portion of the shifts in the molecular orbital binding energies takes place during the adsorption of the first two molecular layers. There may be similar perturbations in the one to four molecular monolayers coverage range for 1,2$\mathrm{PCB}_{10} \mathrm{H}_{11}$, but these are not as significant as observed in 1,2$\mathrm{C}_{2} \mathrm{~B}_{10} \mathrm{H}_{12}$. Such symmetric shifts away from the Fermi level

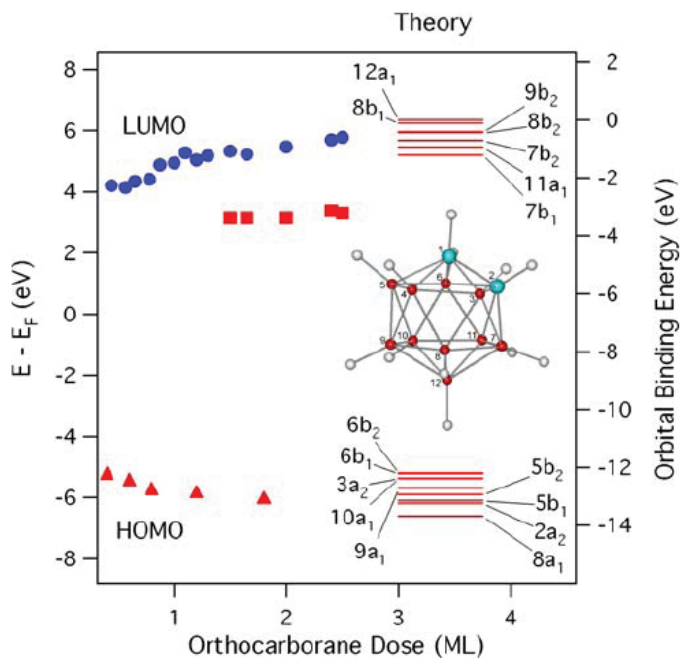

FIGURE 5 The binding energies of the HOMO (triangles), the LUMO (circles), and the exopolyhedral state (squares)of 1,2- $\mathrm{C}_{2} \mathrm{~B}_{10} \mathrm{H}_{12}$ on $\mathrm{Cu}(100)$, referenced to the substrate Fermi level, as a function of $1,2-\mathrm{C}_{2} \mathrm{~B}_{10} \mathrm{H}_{12}$ coverage. Included are the HOMO and LUMO molecular orbital energies of the free clusters which have been derived from MNDO (modified neglect of differential overlap) calculations [7, 10, 19, 20]. of both the occupied and unoccupied states are characteristic of final state effects $[39,52,53]$. It is difficult to invoke initial state effects when the molecular orbitals of the $1,2-\mathrm{C}_{2} \mathrm{~B}_{10} \mathrm{H}_{12}$ are only slightly perturbed upon condensation. This is not observed with the 1,2- $\mathrm{PCB}_{10} \mathrm{H}_{11}$ which do not shift, but the suppression of final state effects upon the photoemission and inverse photoemission of 1,2- $\mathrm{PCB}_{10} \mathrm{H}_{11}$ molecular films may be due to the proximity of the LUMO and exopolyhedra states (discussed below) to the Fermi level which is not the case for 1,2- $\mathrm{C}_{2} \mathrm{~B}_{10} \mathrm{H}_{12}$.

Apart from an unoccupied state that appears very close to the Fermi level in the inverse photoemission spectra, molecular orbital features observed in photoemission and inverse photoemission from the thick $1,2-\mathrm{PCB}_{10} \mathrm{H}_{11}$ molecular films are in excellent agreement with the theoretical semi-empirical molecular orbital calculations, indicated at the bottom of Fig. $3 \mathrm{~b}$.

\section{Exopolyhedral states?}

The placement of the Fermi level within the HOMOLUMO gap is possibly due to impurities and molecular fragments, but this is difficult to reconcile with the data. At the onset of multilayer growth, a weak state appears within the HOMO-LUMO gap at approximately $0.7 \mathrm{eV}$ above the Fermi level, as indicated in Figs. 2 and 3b. We see from Fig. 4, the binding energy of this feature, relative to the Fermi level, is coverage independent, much like the LUMO and HOMO states. Since there is no counterpart to this state in the molecular orbitals of $1,2-\mathrm{PCB}_{10} \mathrm{H}_{11}$, we must conclude that it is an exopolyhedral state and possibly extramolecular. This state could arise from defects, molecular misorientation, or from the loss of exopolyhedral hydrogen. An alternative possibility is an extrinsic state arising from cluster-cluster hybridization. A similar state is observed within the HOMO-LUMO gap at approximately $3 \mathrm{eV}$ above the Fermi level in $1,2-\mathrm{C}_{2} \mathrm{~B}_{10} \mathrm{H}_{12}$ molecular films [7, 17, 39], as seen in Fig. 3a.

The exopolyhedral state persists beyond a few monolayers provided the growth rate is slow. Only when thick films are grown at high growth rates is the exopolyhedral state absent from the inverse photoemission (IPES) spectra. This is evident by comparing the inverse spectra of a 6.8 monolayer thick film, grown at rapid rate, with the 5.6 and 12.2 monolayer thick films grown at slower rates, in Fig. 2. If thick films are annealed at low temperatures $(250 \mathrm{~K})$, the exopolyhedral state returns, while the LUMO density of states is left largely unperturbed. It is clear that this exopolyhedral state cannot be the LUMO since the LUMO should be independent of order within the film. Furthermore, the good agreement between theory and experiment indicates that solid state effects are minimal in the thicker molecular films.

\section{Vibrational modes}

Another test of weak molecular interactions between molecules is to examine the vibrational modes. In Fig. 6, we compare the high resolution infra-red absorption through 1,2- 


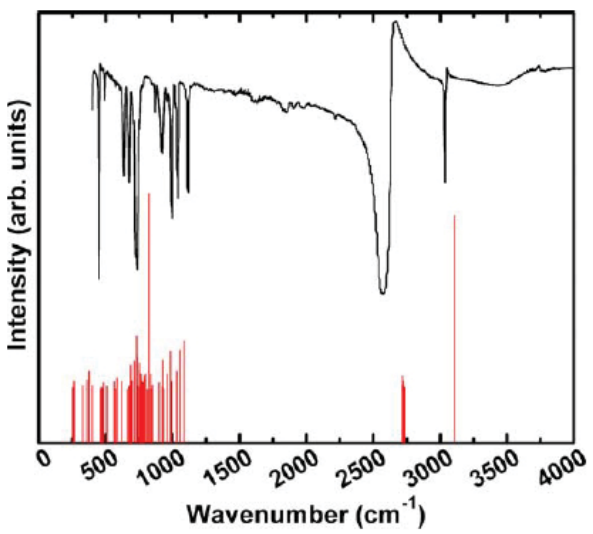

FIGURE 6 The infra-red absorption spectra of $1,2-\mathrm{PCB}_{10} \mathrm{H}_{11}$, as a function of energy in $\mathrm{cm}^{-1}$. The calculated vibrational modes are shown as bars at the bottom of the figure. The assignments and values are summarized in Table 2.

$\mathrm{PCB}_{10} \mathrm{H}_{11}$ crystals with the calculated vibrational modes. There are obviously many more calculated modes than observed as a number of vibrational modes are not strongly dipole active. In general, though, the agreement between theory and experiment is quite good, as summarized in Table 2. The only indication of solid state effects is the generally slightly softer (smaller energy) of the observed vibrational modes when compared to expectation.

The various $v(\mathrm{~B}-\mathrm{H})$ stretch modes are not degenerate, leading to a broader and intense vibrational band at 2575 $\mathrm{cm}^{-1}$. This is expected as the distortion of the cage by the polyhedral phosphorus is significant. A somewhat similar effect is also observed for the various $v(\mathrm{~B}-\mathrm{H})$ stretch modes of $1,2-\mathrm{C}_{2} \mathrm{~B}_{10} \mathrm{H}_{12}$ resulting in a number of closely lying vibrational bands between 2559 to $2623 \mathrm{~cm}^{-1}$ [54-56]. The strong bending $\delta(\mathrm{HCB})$ mode $1120 \mathrm{~cm}^{-1}$ observed for $1,2-\mathrm{PCB}_{10} \mathrm{H}_{11}$ has a similar loss energy of about $1140 \mathrm{~cm}^{-1}$ for $1,2-\mathrm{C}_{2} \mathrm{~B}_{10} \mathrm{H}_{12}$ [54-56]. Similarly, the $v(\mathrm{C}-\mathrm{H})$ stretch mode observed at 3040 $\mathrm{cm}^{-1}$ for $1,2-\mathrm{PCB}_{10} \mathrm{H}_{11}$ has its counterpart at about $3064 \mathrm{~cm}^{-1}$ for $1,2-\mathrm{C}_{2} \mathrm{~B}_{10} \mathrm{H}_{12}$ [54-56].

The large number of bending and rocking $\mathrm{B}-\mathrm{H}$ vibrational modes expected between $760 \mathrm{~cm}^{-1}$ and $848 \mathrm{~cm}^{-1}$ are generally not observed in our high resolution IR absorption as they are not very dipole active, although the bending $\mathrm{B}-\mathrm{H}$ mode that is coupled to a skeletal B-B mode at $824 \mathrm{~cm}^{-1}$ is more strongly dipole active and is observed at $870 \mathrm{~cm}^{-1}$. Some of these modes are observed for $1,2-\mathrm{PCB}_{10} \mathrm{H}_{11}$ in solution by Raman spectroscopy [57], as summarized in Table 2. The IR absorption loss observed at $735 \mathrm{~cm}^{-1}$ contains both B-H modes that are coupled to a skeletal mode as well as $\mathrm{C}-\mathrm{B}$ and $\mathrm{P}-$ $\mathrm{C}$ stretching modes, as indicated in Table 2, thus explain the somewhat greater width of this feature.

The vibrational modes between $250 \mathrm{~cm}^{-1}$ and $750 \mathrm{~cm}^{-1}$, noted previously for $1,2-\mathrm{PCB}_{10} \mathrm{H}_{11}$ [37], are related to skeletal modes. The breathing mode we observe at $735 \mathrm{~cm}^{-1}$ has been previously observed at $740 \mathrm{~cm}^{-1}$ for $1,2-\mathrm{PCB}_{10} \mathrm{H}_{11}$ in solution [c], although semi-empirical theory places the mode at 727 $\mathrm{cm}^{-1}$ [40]. The observed loss is in generally good agreement with our calculated values. Many of these modes that are not observed in the molecular solid are observed in solution, particularly if coupled to a wagging or bending B-H mode [57]. These differences (as summarized in Table 2) could be due to a response from the solution (increasing the dipole response in IR), or cage screening in the solid state (decreasing the dipole response for the condensed molecular film). The latter explanation, invoking a response of the molecular solid to some vibrational modes, is also suggested by the fact that we do observe some modes in our infrared absorption spectra that are not observed in solution (although they are observed in the solution Raman spectrum of 1,2- $\mathrm{PCB}_{10} \mathrm{H}_{11}$ [57]) when the dipole change involved is large.

In spite of some differences between our infra-red absorption spectrum of the 1,2- $\mathrm{PCB}_{10} \mathrm{H}_{11}$ in a molecular solid and in the previously obtained results for $1,2-\mathrm{PCB}_{10} \mathrm{H}_{11}$ in solution, there is no strong evidence of strong solid state intermolecular interactions. In particular, we find no evidence from the vibrational spectra of dipole-dipole coupling given the good agreement of theory with experiment. While intermolecular interactions are certainly implicated in the combined photoemission and inverse photoemission studies undertaken, the absence of dipole-dipole coupling in the vibronic structure is consistent with disorder in molecular orientation observed in X-ray diffraction.

\section{Semiconductor growth and characterization}

We find that the electronic structure (molecular orbitals) of the 1,2- $\mathrm{PCB}_{10} \mathrm{H}_{11}$ closo-carborane molecular films is reflected in the tendency of $1,2-\mathrm{PCB}_{10} \mathrm{H}_{11}$ to form a more $n$-type semiconductor upon decomposition, when compared to the semiconducting boron carbide formed from the decomposition of $1,2-\mathrm{C}_{2} \mathrm{~B}_{10} \mathrm{H}_{12}$, orthocarborane. We have fabricated a number of diodes by plasma enhanced chemical vapor deposition (PECVD) including heterojunction diodes with silicon $[1-4,15,16]$ and homojunction diodes [13] of boron-carbide as well as diodes made from two polytypes of boron-carbide [5-7]. The latter device fabrication was a further demonstration that $n$-type and $p$-type boron-carbides are formed from the decomposition of metacarborane and orthocarborane respectively [7]. Thus to confirm that 1,2- $\mathrm{PCB}_{10} \mathrm{H}_{11}$ forms an $n$-type boron-carbide similar to that found from the decomposition of metacarborane $\left(1,7-\mathrm{C}_{2} \mathrm{~B}_{10} \mathrm{H}_{12}\right)$ or a $p$-type boroncarbide, as occurs from the decomposition of orthocarborane $\left(1,2-\mathrm{C}_{2} \mathrm{~B}_{10} \mathrm{H}_{12}\right)$, we fabricated a number of different diodes on sputtered silicon surfaces from silicon wafers of various doping levels with $p$ or $n$ dopants.

The diodes were constructed using PECVD, as described for other boron carbide heterojunction diodes with silicon [1$4,14-16]$. These heterojunction diodes formed from the plasma-enhanced decomposition of $1,2-\mathrm{PCB}_{10} \mathrm{H}_{11}$ (as the source gas carborane) deposited on cleaned, etched $p$-type silicon, compare favorably (Fig. 7a) with devices fabricated from other carboranes $[1-4,15,16]$, but show poor diode characteristics when formed on an $n$-type silicon (Fig. 7b).

This is not compelling proof of the majority character for 


\begin{tabular}{|c|c|c|c|c|}
\hline 1.2- $\mathrm{PCB}_{10} \mathrm{H}_{11}$ mode assignment & $\begin{array}{l}1,2-\mathrm{PCB}_{10} \mathrm{H}_{11} \\
\text { mode dipole }\end{array}$ & $\begin{array}{l}1,2-\mathrm{PCB}_{10} \mathrm{H}_{11} \\
\text { theory }\left(\mathrm{cm}^{-1}\right)\end{array}$ & $\begin{array}{l}\text { 1,2-PCB }{ }_{10} \mathrm{H}_{11} \\
\text { IR } \operatorname{expt}\left(\mathrm{cm}^{-1}\right)\end{array}$ & $\begin{array}{c}1,2-\mathrm{PCB}_{10} \mathrm{H}_{11} \\
\text { Raman expt. }\left(\mathrm{cm}^{-1}\right)\end{array}$ \\
\hline Skeletal vibration, v-PC, v-PB & 0.1236 & 254.45 & & \\
\hline Skeletal vibration, $v-\mathrm{PC}, v-\mathrm{PB}$ & 0.2389 & 262.34 & & \\
\hline Skeletal vibration, $v-\mathrm{PC}, v$-PB & 0.1975 & 327.78 & & \\
\hline Skeletal vibration, v-PC, v-PB & 0.3065 & 357.25 & & $350 \dagger$ \\
\hline Skeletal vibration, v-PC, v-PB & 0.4289 & 376.33 & & \\
\hline Skeletal vibration, $8, \omega-\mathrm{BB}$ & 0.1962 & 398.89 & & $390 \dagger$ \\
\hline Skeletal vibration, $t$-BB & 0.0550 & 464.97 & & $445 \dagger$ \\
\hline Skeletal vibration, $v$-BB & 0.1392 & 468.95 & $449^{*}, 455 \dagger$ & \\
\hline Skeletal vibration, $r$-BB & 0.039965235 & 475.54 & & $460 \dagger$ \\
\hline Skeletal vibration, v-BB & 0.25919537 & 481.95 & $490 \dagger$ & $480 \dagger$ \\
\hline Skeletal vibration, $r$-BB & 0.186307622 & 509.63 & & \\
\hline Skeletal vibration, $\delta, \omega$-PB & 0.276493834 & 562.19 & $492^{*}, 490 \dagger$ & \\
\hline Skeletal vibration, $r$-BB & 0.067661289 & 573.03 & & $565 \dagger$ \\
\hline Skeletal vibration, $t$-CB & 0.341263095 & 586.48 & $636^{*} .635 \dagger$ & $630 \dagger$ \\
\hline Skeletal vibration, $v$-BP & 0.27956459 & 623.43 & & \\
\hline Skeletal vibration, $8, \omega$-BB & 0.004657252 & 663.86 & & $670 \dagger$ \\
\hline Skeletal vibration, $v-\mathrm{PC}$ & 0.177247539 & 676.85 & & \\
\hline Skeletal vibration, v-BB & 0.492405737 & 687.3 & $677 * 680 \dagger$ & \\
\hline Skeletal vibration, $v-\mathrm{CB}, v-\mathrm{BB}$ & 0.28595421 & 695.6 & & \\
\hline Skeletal vibration, v-PC, v-PB & 0.53663032 & 716.35 & $710 \dagger$ & \\
\hline Skeletal vibration \& \&-BH & 0.73259772 & 730.87 & $735^{*}$ & $730 \dagger$ \\
\hline Skeletal vibration \& \&-BH & 0.579624258 & 732.76 & & \\
\hline Skeletal vibration $r$-BB \& $8, \omega-\mathrm{HB}$ & 0.183223197 & 736.5 & & \\
\hline Skeletal vibration, $\delta, \omega$-HBB & 0.12469186 & 749.28 & & \\
\hline$\omega$-HB & 0.434167468 & 752.58 & $754^{*}, 745 \dagger$ & $740 \dagger$ \\
\hline $8, \omega-\mathrm{HBB}$ & 0.51992411 & 754.54 & & \\
\hline$\delta, \omega-\mathrm{HBB}$ & 0.14403871 & 760.46 & & \\
\hline $8, \omega-\mathrm{HBB}$ & 0.385500337 & 763.86 & & \\
\hline$\omega-\mathrm{HB}$ & 0.396480138 & 765.34 & $765 \dagger$ & $760 \dagger$ \\
\hline$\omega$-HB & 0.288734099 & 768.96 & & \\
\hline$\omega$-HB & 0.258272472 & 774.84 & & \\
\hline$\omega$-HB & 0.085035875 & 776.85 & & $770 \dagger$ \\
\hline$r$-HB & 0.264371821 & 785.7 & & \\
\hline$r$-HB & 0.369684541 & 785.9 & & \\
\hline$r$-HB & 0.324514992 & 796.49 & & \\
\hline$r-\mathrm{HB}, r-\mathrm{HC}$ & 0.39563075 & 798.67 & & $820 \dagger$ \\
\hline$r$-HB & 0.015542844 & 812.35 & & \\
\hline $8, \omega-\mathrm{HB}, t-\mathrm{BB}$ & 1.407074216 & 824.16 & $870^{*}, 870 \dagger$ & $870 \dagger$ \\
\hline$\omega-\mathrm{HB}$ & 0.035896936 & 836.47 & & \\
\hline$\omega-\mathrm{HB}$ & 0.393120567 & 838.52 & & \\
\hline$\omega-\mathrm{HB}$ & 0.076250836 & 847.88 & & \\
\hline Skeletal vibration, $v$-BB & 0.206048562 & 851.31 & & \\
\hline Skeletal vibration, $t$-BBB & 0.258667141 & 899.05 & $912 *$ & $910 \dagger$ \\
\hline Skeletal vibration, $t$-CBB & 0.156959517 & 924.91 & & \\
\hline Skeletal vibration, 8-BB & 0.54298697 & 928.78 & $926^{*}, 925 \dagger$ & $925 \dagger$ \\
\hline Skeletal vibration, $t$-BB & 0.067104843 & 933.75 & $940 \dagger$ & $930 \dagger$ \\
\hline$r$-HCB & 0.395699646 & 962.51 & $960 \dagger$ & $960 \dagger$ \\
\hline$\delta, \omega-\mathrm{CH}$ & 0.62303272 & 985.11 & $997 * .1000 \dagger$ & \\
\hline Skeletal vibration, $r$-BB & 0.28125684 & 992.52 & & $990 \dagger$ \\
\hline Skeletal vibration, $v-C B B$ & 0.427869373 & 1031.21 & & \\
\hline$r$-HCB & 0.631458019 & 1058.65 & $1040^{*}$ & $1075 \dagger$ \\
\hline $8-\mathrm{HCB}$ & 0.700933278 & 1087.07 & $1120^{\circ}, 1120 \dagger$ & \\
\hline レーBH & 0.226011504 & 2714.81 & & \\
\hline レーBH & 0.363927328 & 2716.7 & & \\
\hline レーBH & 0.140576349 & 2722.46 & & \\
\hline レーBH & 0.205819071 & 2723.38 & & \\
\hline レーBH & 0.291586917 & 2723.58 & & \\
\hline レーBH & 0.271812822 & 2725.36 & $2570^{*}, 2570 \dagger$ & $2560 \dagger$ \\
\hline レーBH & 0.188638755 & 2726.22 & & \\
\hline レーBH & 0.150908283 & 2729.57 & & \\
\hline レBH & 0.115618078 & 2732.46 & & \\
\hline レーBH & 0.120151155 & 2735.78 & & \\
\hline レCH & 1.326609155 & 3110.23 & $3040^{*}, 3050 \dagger$ & $3050 \dagger$ \\
\hline
\end{tabular}

TABLE 2 Comparison of calculated vibrational modes of closo-1-phospha-2-carbadodecaborane $\left(1,2-\mathrm{PCB}_{10} \mathrm{H}_{11}\right)$ with high resolution infrared absorption. The vibrational modes are roughly identified by $v_{\mathrm{s}, \mathrm{a}}$ for symmetry or antisymmetric stretching modes, $\delta$ for bending modes, $w$ for wagging modes, $r$ for rocking modes, and $t$ for twisting modes but because of the low point group symmetry and the coupling to skeletal modes, the assignments are sometimes ambiguous. $\{*\}$ indicates this work and $\{\dagger\}$ refers to reference [57]. 


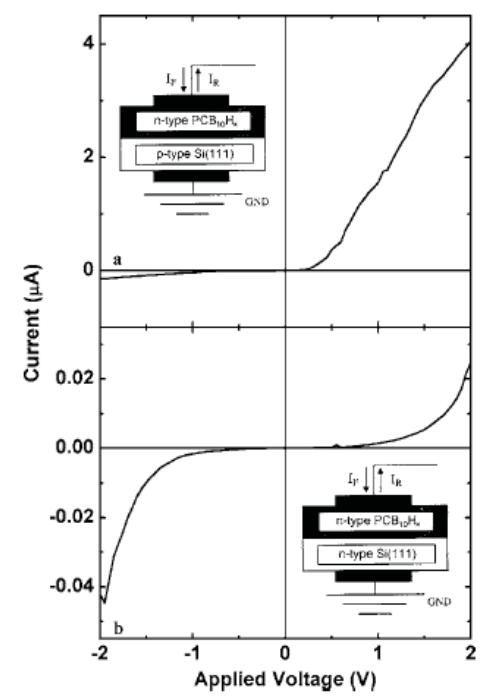

FIGURE 7 Heterojunctions formed by the plasma enhanced decomposition of 1,2- $\mathrm{PCB}_{10} \mathrm{H}_{11}$ on $p$-type silicon (boron doped) with a resistivity of 10-20 $\Omega \mathrm{cm}$ (a), and on $n$-type silicon (phosphorous doped) with a resistivity $2-30 \Omega \mathrm{cm}$ (b). Note that (a) shows the typical rectifying characteristics of a diode while (b) does not.

this class of a heteroatom semiconducting boron carbide, but does suggest that an $n$-type boron carbide may be formed from 1,2- $\mathrm{PCB}_{10} \mathrm{H}_{11}$. If the decomposition of 1,2- $\mathrm{PCB}_{10} \mathrm{H}_{11}$ formed a $p$-type material, then while a rectifying $p-p+$ heterojunction diode is certainly possible, the diode characteristics observed must result in a material less $p$-type than the silicon substrate. Similarly, if the decomposition of 1,2- $\mathrm{PCB}_{10} \mathrm{H}_{11}$ does result in a $p$-type material, it is then difficult to understand why the $p-$ $n$ junction heterojunction diode should not show better rectification. Accordingly, we are left to conclude that the decomposition of 1,2- $\mathrm{PCB}_{10} \mathrm{H}_{11}$ most likely leads to the formation of an $n$-type semiconductor. It must be pointed out that this is not a direct measurement of $n$-type character in the semiconductor formed from the PECVD of 1,2-PCB ${ }_{10} \mathrm{H}_{11}$, which must be confirmed with further measurements. Nevertheless, it appears that $1,2-\mathrm{PCB}_{10} \mathrm{H}_{11}$ is similar to metacarborane and orthocarborane, where the position of the Fermi level in their respective molecular films is consistent with the formation of $n$-type and $p$-type boron-carbides from the decomposition of metacarborane and orthocarborane of the respective carborane [7].

This similarity of the "boron carbide" semiconductor formed from the plasma enhanced decomposition of 1,2$\mathrm{PCB}_{10} \mathrm{H}_{11}$ to the boron carbide semiconductor formed from the decomposition of metacarborane $\left(1,7-\mathrm{C}_{2} \mathrm{~B}_{10} \mathrm{H}_{12}\right)$, is demonstrated by our ability to make a diode from the deposition of a $\mathrm{PCB}_{10} \mathrm{H}_{x}$ film, by the partial dehydrogenation of 1,2$\mathrm{PCB}_{10} \mathrm{H}_{11}$ through PECVD, on $\mathrm{C}_{2} \mathrm{~B}_{10} \mathrm{H}_{x}$, derived from orthocarborane $\left(1,2-\mathrm{C}_{2} \mathrm{~B}_{10} \mathrm{H}_{12}\right)$ through PECVD. These diodes do rectify (as seen in Fig. ), but with relatively large leakage currents (compared to the forward current). The leakage currents appear significant, particularly when compared all boron carbide diodes formed from the PECVD semiconducting

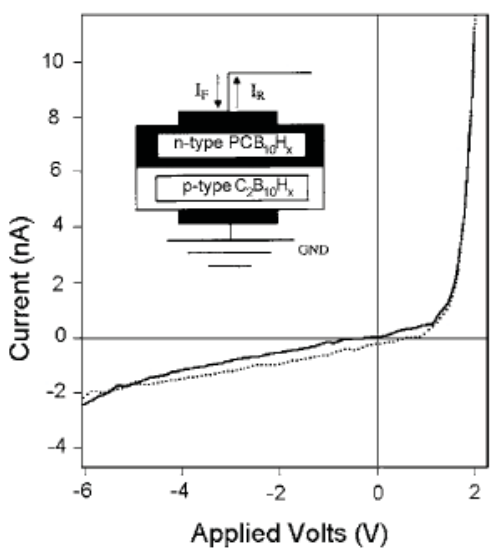

FIGURE 8 Heterojunctions formed by the plasma enhanced decomposition of 1,2- $\mathrm{PCB}_{10} \mathrm{H}_{11}$ on $p$-type boron carbide formed by the plasma enhanced decomposition of $1,2-\mathrm{C}_{2} \mathrm{~B}_{10} \mathrm{H}_{11}$. Note, some photoconductivity is observed in these diodes under illumination of white visible light (dashed line) compared to $I(V)$ curves taken in the dark (solid line).

boron carbides from metacarborane $\left(1,7-\mathrm{C}_{2} \mathrm{~B}_{10} \mathrm{H}_{12}\right)$ and orthocarborane $\left(1,2-\mathrm{C}_{2} \mathrm{~B}_{10} \mathrm{H}_{12}\right)$, respectively [5-7]. The $n$-PCB${ }_{10} \mathrm{H}_{x} / p-\mathrm{C}_{2} \mathrm{~B}_{10} \mathrm{H}_{x}$ diodes are another, more compelling, demonstration of the tendency of $1,2-\mathrm{PCB}_{10} \mathrm{H}_{11}$ to form a more $n$ type semiconductor, upon decomposition, than the semiconducting boron carbide formed from the decomposition of 1,2$\mathrm{C}_{2} \mathrm{~B}_{10} \mathrm{H}_{12}$, orthocarborane.

The $n-\mathrm{PCB}_{10} \mathrm{H}_{x} / p-\mathrm{C}_{2} \mathrm{~B}_{10} \mathrm{H}_{x}$ diodes, like the boron carbide semiconductor $n-\mathrm{C}_{2} \mathrm{~B}_{10} \mathrm{H}_{x} / p-\mathrm{C}_{2} \mathrm{~B}_{10} \mathrm{H}_{x}$ diodes, also exhibit fourth quadrant conductivity when illuminated with visible light, as seen in Fig. 8. Although generally very small, some photoconductivity is observed in these diodes under illumination of white visible light (dashed line), when compared to $I(V$ )curves taken in the dark (solid line), as indicated in Fig. 8.

The origin of the larger leakage currents from $\mathrm{PCB}_{10} \mathrm{H}_{x}$ / $\mathrm{C}_{2} \mathrm{~B}_{10} \mathrm{H}_{x}$ diodes is, as yet, unknown, but $\mathrm{PCB}_{10} \mathrm{H}_{x}$ films, formed by the partial dehydrogenation of $1,2-\mathrm{PCB}_{10} \mathrm{H}_{11}$ through PECVD, does appear to have a smaller sheet resistance $\left(10^{8} \Omega \mathrm{cm}\right)$ compared to the corresponding $\mathrm{C}_{2} \mathrm{~B}_{10} \mathrm{H}_{x}$ formed by the partial dehydrogenation of metacarborane (1,7$\left.\mathrm{C}_{2} \mathrm{~B}_{10} \mathrm{H}_{12}\right)$ through PECVD $\left(10^{11} \Omega \mathrm{cm}\right.$ to $\left.10^{12} \Omega \mathrm{cm}\right)$. At this point we can only speculate, but it may well be that $\mathrm{PCB}_{10} \mathrm{H}_{x}$ films may be far more $n$-type than the corresponding $\mathrm{C}_{2} \mathrm{~B}_{10} \mathrm{H}_{x}$ formed by the partial dehydrogenation of metacarborane (1,7$\mathrm{C}_{2} \mathrm{~B}_{10} \mathrm{H}_{12}$ ) through PECVD. Further investigation of the carrier concentrations is clearly indicated. Nonetheless, this appears to be the first report of a semiconducting $\mathrm{PCB}_{10} \mathrm{H}_{x}$, from which diode fabrication is clearly possible. The promise of a semiconducting $\mathrm{P}_{x} \mathrm{CB}_{10} \mathrm{H}_{x}$ suggested by earlier studies [14] and, more importantly, the ability to be able to obtain consistently doped thin films, now appears to be realized.

\section{Summary}

The placement of the chemical potential closer to the conduction band edge (the lowest unoccupied molecular orbital 
of the 1,2- $\mathrm{PCB}_{10} \mathrm{H}_{11}$ molecular film), and the presence of a defect state just above the Fermi level(that is dependent upon annealing conditions) argues for strong solid-state effects in the molecular film. On the other hand, the absence of band bending like effects, the striking similarity of the $1,2-\mathrm{PCB}_{10} \mathrm{H}_{11}$ induced photoemission and inverse photoemission features to the molecular orbitals expected for an isolated 1,2- $\mathrm{PCB}_{10} \mathrm{H}_{11}$ molecule, the IR absorption spectra resemblance to the expected vibrational spectrum and the very low sticking coefficient for adsorption suggest otherwise. The molecular interactions in a 1,2- $\mathrm{PCB}_{10} \mathrm{H}_{11}$ molecular film generally to appear to resemble that of weak chemisorption or physisorption.

The electronic structure of the molecular carborane films is not always a good indicator of the semiconducting properties resultant boron-carbide $\mathrm{C}_{2} \mathrm{~B}_{10} \mathrm{H}_{x^{\prime}}$, formed by the partial dehydrogenation and deposition of corresponding carbide through PECVD $[58,59]$. Yet, for the $n$-type boron carbide formed from metacarborane $\left(1,7-\mathrm{C}_{2} \mathrm{~B}_{10} \mathrm{H}_{12}\right)[7,17]$, the $p$-type boron-carbide, derived from the decomposition of orthocarborane $\left(1,2-\mathrm{C}_{2} \mathrm{~B}_{10} \mathrm{H}_{12}\right)[7,17]$, the placement of the Fermi level in the electronic structure of the molecular film does appear to be correlated. The tendency of 1,2- $\mathrm{PCB}_{10} \mathrm{H}_{11}$ to form a more $n$-type semiconductor upon decomposition, when compared to the semiconducting boron carbide formed from the decomposition of $1,2-\mathrm{C}_{2} \mathrm{~B}_{10} \mathrm{H}_{12}$, orthocarborane suggests that the placement of the Fermi level, in molecular films of $1,2-\mathrm{PCB}_{10} \mathrm{H}_{11}$, may also provide an indication of the resulting semiconducting thin film.

ACKNOWLEDGEMENTS - This research was supported by the National Science Foundation through grants \#ECS-0300018, the Office of Naval Research, the Nebraska Research Initiative and the U. S. Department of Energy National Nuclear Security Administration Office of Nonproliferation Research and Engineering (NA-22) through Pacific Northwest National Laboratory. D. I. D. thanks the ORS and the University of Salford for a studentship. The authors are grateful to Y. B Losovyj, Orhan Kizilkaya, A. N. Caruso and Danqin Feng for their comments and assistance. The photoemission and infrared absorption was undertaken at the Center for Advance Microstructures and Devices, which is supported by the State of Louisiana.

\section{REFERENCES}

1 B. W. Robertson, S. Adenwalla, A. Harken, P. Welsch, J. I. Brand, P. A. Dowben, J. P. Claassen, Appl. Phys. Lett. 80, 3644 (2002)

2 B. W. Robertson, S. Adenwalla, A. Harken, P. Welsch, J. I. Brand, J. P. Claassen, N. M. Boag, P. A. Dowben, In: Advances in Neutron Scattering Instrumentation, ed. by I. S. Anderson, B. Guérard, Proc. SPIE 4785, 226 (2002)

3 S. Adenwalla, R. Billa, J. I. Brand, E. Day, M. J. Diaz, A. Harken, A. McMullen-Gunn, R. Padmanabhan, B. W. Robertson, In: Penetrating Radiation Systems and Applications V, Proc. SPIE 5199, 70 (2003)

4 A. D. Harken, E. E. Day, B. W. Robertson, S. Adenwalla, Jpn. J. Appl. Phys. 44, 444 (2005)

5 K. Osberg, N. Schemm, S. Balkir, J. I. Brand, S. Hallbeck, P. Dowben, IEEE Sensors Journal (2006), in press

6 S. Balkir, N. Schemm, K. Osberg, R. W. Fairchild, A. Pattanayak,
M. S. Bikah, J. I. Brand, A. D. Harken, B. W. Robertson, A. N. Caruso, P. A. Dowben, J. Mater. Sci. Eng. B, submitted

7 A. N. Caruso, R. B. Billa, S. Balaz, J. I. Brand, P. A. Dowben, J. Phys.: Condens. Matter 16, L139 (2004)

8 P. Lunca-Popa, J. I. Brand, S. Balaz, L. G. Rosa, N. M. Boag, M. Bai, B. W. Robertson, P. A. Dowben, J. Phys. D Appl. Phys. 38, 1248 (2005)

9 H. Takizawa, N. Haze, K. Okamoto, K. Uheda, T. Endo, Mater. Res. Bull. 37, 113 (2002)

10 U. Kuhlmann, H. Werheit, J. Pelloth, W. Keune, T. Lundstrom, Phys. Stat. Solidi B 187, 43 (1995)

11 U. Kuhlmann, H. Werheit, T. Dose, T. Lundstrom, J. Alloys Compd. 186, 187 (1992)

12 H. Werheit, R. Schmechel, V. Kueffel, T. Lundstrom, J. Alloys Compd. 262, 372 (1997)

13 S.-D. Hwang, K. Yang, P. A. Dowben, A. A. Ahmad, N. J. Ianno, J. Z. Li, J. Y. Lin, H. X. Jiang, D. N. McIlroy, Appl. Phys. Lett. 70, 1028 (1997)

14 D. N. McIlroy, S.-D. Hwang, K. Yang, N. Remmes, P. A. Dowben, A. A. Ahmad, N. J. Ianno, J. Z. Li, J. Y. Lin, H. X. Jiang, Appl. Phys. A 67, 335 (1998)

15 S.-D. Hwang, N. B. Remmes, P. A. Dowben, D. N. McIlroy, J. Vac. Sci. Technol. B 14, 2957 (1996)

16 S.-D. Hwang, N. Remmes, P. A. Dowben, D. N. McIlroy, J. Vac. Sci. Technol. A 15, 854 (1997)

17 A. N. Caruso, L. Bernard, B. Xu, P. A. Dowben, J. Phys. Chem. B 1079, 620 (2003)

18 A. P. Hitchcock, S. G. Urquhart, A. T. Wen, A. L. D. Kilcoyne, T. Tyliszczak, E. Ruhl, N. Kosugi, J. D. Bozek, J. T. Spencer, D. N. McIlroy, P. A. Dowben, J. Phys. Chem. B 101, 3483 (1997)

19 J. L. Little, J. T. Moran, L. J. Todd, J. Am. Chem. Soc. 89, 5495 (1967)

20 W. H. Knoth, J. L. Little, J. R. Lawrence, F. D. Scholer, L. J. Todd, Inorg. Synth. 11, 33 (1968)

21 http://www. katchem. cz/

22 H. Zeng, D. Byun, J. Zhang, G. Vidali, M. Onellion, P. A. Dowben, Surf. Sci. 313, 239 (1994)

23 P. W. Erdman, E. C. Zipf, R eV. Sci. Instrum. 53, 225 (1982)

24 O. Kizilkaya, J. D. Scott, E. Morikawa, J. D. Garber, R. S. Perkins, R eV. Sci. Instrum. 76, 013703 (2005)

25 closo-1,12- $\mathrm{PCB}_{10} \mathrm{H}_{11}$, closo-1,12- $\mathrm{C}_{2} \mathrm{~B}_{10} \mathrm{H}_{12}$ : V. S. Mastryukov, E. G. Atavin, L. V. Vilkov, A. V. Golubinskii, V. N. Kalinin, G. G. Zhigar eVa, L. I. Zakharkin, J. Mol. Struct. 56, 139 (1979)

26 closo- $1,2-\mathrm{C}_{2} \mathrm{~B}_{10} \mathrm{H}_{12}$, closo-1,7- $\mathrm{C}_{2} \mathrm{~B}_{10} \mathrm{H}_{12}$, closo-1,12- $\mathrm{C}_{2} \mathrm{~B}_{10} \mathrm{H}_{12}$ : A. R. Turner, H. E. Robertson, K. B. Borisenko, D. W. H. Rankin, M. A. Fox, J. Chem. Soc., Dalton Trans. 1310 (2005)

27 M. G. Davidson, T. G. Hibbert, J. A. K. Howard, A. Mackinnon, K. Wade, Chem. Commun. 2285 (1996)

28 1-Cp-closo-1,2,4,5-FePC ${ }_{2} \mathrm{~B}_{8} \mathrm{H}_{10}$ : B. Štibr, J. Holub, M. Bakardji eV, I. Pavlik, O. L. Tok, I. Cisařová, B. Wrackmeyer, M. Herberhold, Chem. Eur. J. 9, 2239 (2003)

29 9,10-Cl ${ }_{2}$-closo-1,7-PCB ${ }_{10} \mathrm{H}_{11}$ : H. S. Wong, W. N. Lipscomb, Inorg. Chem. 14, 1350 (1975)

30 9,10-I - $_{2}$ loso-1,7-PCB ${ }_{10} \mathrm{H}_{11}$ : L. I. Zakharkin, G. G. Zhigar eVa, K. A. Lysenko, M. Y. Antipin, P. V. Petrovskii, Russ. J. Gen. Chem. 71, 196 (2001)

31 3,6- $\mathrm{Cl}_{2}-1,2-\mathrm{P}_{2} \mathrm{~B}_{10} \mathrm{H}_{8}$ B. Grüner, D. Hnyk, I. Cisařová, Z. Plzák, B. Štibr, J. Chem. Soc. Dalton Trans. 2954 (2002) 
32 [10-Cl-nido-7,8,9- $\left.\mathrm{PC}_{2} \mathrm{~B}_{8} \mathrm{H}_{9}\right]^{-}$: B. Štibr, J. Holub, M. Bakardji eV, D. Hnyk, O. L. Tok, W. Milius, B. Wrackmeyer, Eur. J. Inorg. Chem. 2320 (2002)

33 E. C. Reynhardt, S. Froneman, Mol. Phys. 74, 61 (1991)

34 O. Yamamuro, M. Hayashi, T. Matsuo, P. Lunkenheimer, J. Chem. Phys. 119, 4775 (2003)

35 S. Lee, D. Li, P. A. Dowben, F. K. Perkins, M. Onellion, J. T. Spencer, J. Am. Chem. Soc. 113, 8444 (1991)

36 L. Bernard, A. N. Caruso, B. Xu, B. Doudin, P. A. Dowben, Thin Solid Films 428, 253 (2003)

37 J. J. P. Stewart, J. Comput. Chem. 10, 209 (1989)

38 J. J. P. Stewart, J. Comput. Chem. 10, 221 (1989)

39 D. N. McIlroy, C. Waldfried, T. McAvoy, J. Choi, P. A. Dowben, D. Heskett, Chem. Phys. Lett. 264, 168 (1997)

40 M. Zhang, Y. Zhao, J. Mol. Struct. Theochem. 545, 105 (2001)

41 K. Park, M. R. Pederson, L. L. Boyer, W. N. Mei, R. F. Sabirianov, X. C. Zeng, S. Bulusu, S. Curran, J. Dewald, E. Day, S. Adenwalla, M. Diaz, L. G. Rosa, S. Balaz, P. A. Dowben, Phys. R eV. B 73, 035109 (2006)

42 E. D. Jemmis, B. Kiran, D. Coffey Jr., Chem. Ber. 130, 1147 (1997)

43 M. De Seta, F. eVangelisti, Phys. R eV. Lett. 71, 2477 (1993)

44 T. Takahashi, S. Suzuki, T. Morikawa, H. Katayama-Yoshida, S. Hasegawa, H. Inokuchi, K. Seki, K. Kikuchi, S. Suzuki, K. Ikemoto, Y. Achiba, Phys. R eV. Lett. 68, 1232 (1992)

45 R. W. Lof, M. A. van Veenendaal, B. Koopmans, H. T. Jonkman, G. A. Sawatzky, Phys. R eV. Lett. 68, 3924 (1992)

46 J. Hölzl, F. K. Schulte, Work Function of Metals, In: Springer Tracts in Modern Physics, Vol. 85, Solid Surface Physics (Springer, 1979) pp. 1-150
47 P. A. Dowben, J. Choi, E. Morikawa, B. Xu, In: Handbook of Thin Films, ed. by H. S. Nalwa (Academic Press, New York 2002) Vol. 2, Chapt. 2, pp. 61-114

48 S. J. Chase, W. S. Basca, M. G. Mitch, L. J. Pilione, J. S. Lannin, Phys. R eV. B 46, 7873 (1992)

49 T. R. Ohno, Y. Chen, S. E. Harvey, G. H. Kroll, P. J. Benning, J. H. Weaver, Phys. R eV. B 44, 13747 (1991)

50 A. J. Maxwell, P. A. Brühwiler, A. Nilsson, N. Mårtensson, P. Rudolf, Phys. R eV. B 49, 10717 (1994)

51 R. L. Linge, D. F. Padowitz, R. E. Jordan, J. D. McNeill, C. B. Harris, Phys. R eV. Lett. 72, 2243 (1994)

52 J. Ortega, F. Flores, Phys. R eV. Lett. 63, 2500 (1989)

53 N. F. Mott, Metal-Insulator Transitions, 2nd edn. (Taylor and Francis, London, 1990)

54 R. M. Paroli, N. T. Kawai, G. Lord, I. S. Butler, D. F. R. Gilson, Inorg. Chem. 28, 1819 (1989)

55 L. A. Leites, Chem. R eV. 92, 279 (1992)

56 D. Salam, M. S. Deleuze, J.-P. François, Chem. Phys. 286, 45 (2003)

57 L. E. Vinogradova, V. I. Kyskin, L. A. Leites, L. I. Zakharkin, Russ. Chem. Bull. 21, 2372 (1972)

58 C. C. Ilie, S. Balaz, L. G. Rosa, J. Zhang, P. Lunca-Popa, C. Bianchetti, R. Tittsworth, J. I. Brand, B. Doudin, P. A. Dowben, Appl. Phys. A 81, 1613 (2005)

59 C. C. Ilie, P. Lunca-Popa, J. Zhang, B. Doudin, P. A. Dowben, Mater. Res. Soc. Symp. Proc. 848, FF6. 5. 1 (2005) 